\title{
BULLYING NO AMBIENTE ESCOLAR: O PAPEL DO PROFES- SOR E DA ESCOLA COMO PROMOTORES DE RESILIÊNCIA
}

BULLYING IN THE SCHOOL ENVIRONMENT: THE ROLE OF THE SCHOOL AND TEACHERS AS RESILIENCE PROMOTERS

\section{Grazielli Fernandes' ${ }^{1}$ Maria Angela Mattar Yunes², Leonidas Roberto Taschetto ${ }^{3}$}

RECEBIDO EM: 16/06/2017 / APROVADO EM: 22/07/2017

DOI: $10.5902 / 2317175827701$

\section{RESUMO}

Este artigo tem como objetivo provocar reflexões sobre o bullying escolar, definido como prática violenta intencional praticada entre pares, com desigualdade de poder, que prejudica as relações humanas, com consequências e mudanças nas características biopsicológicas dos envolvidos. O relato de experiência apresenta uma atividade desenvolvida por uma professora de uma escola pública do sul do Brasil, a qual solicitou aos seus alunos, no início do ano letivo, a produção de texto intitulada "Quem sou eu?". O texto de um dos alunos sobre seu sofrimento de voltar para a escola por sofrer bullying, motivou a docente a desenvolver um projeto de intervenção. Ao final do ano letivo, foi solicitada nova produção de texto, por meio do qual se constatou o desenvolvimento positivo do referido estudante. O relato dessa experiência apresenta as duas produções do aluno e o projeto de intervenção desenvolvido no ambiente escolar.

Palavras-chave: Bullying; intervenção; risco e proteção; resiliência.

1 Mestra em Educação pela Universidade La Salle - Unilasalle e graduada em Letras - Língua Portuguesa pela Universidade Federal de Santa Maria (2008). E-mail: graziellifernandes@gmail.com

2 Graduada em Psicologia pelo Instituto Unificado Paulista (1977), mestrado em Psicologia do Desenvolvimento pela University of Dundee, Escócia (1991) e doutorado em Educação (Psicologia da Educação) pela Pontifícia Universidade Católica de São Paulo (2001).E-mail: mamyunes@yahoo.com.br.

3 Pesquisador CNPq. Doutor em Educação pela Universidade Federal do Rio Grande do Sul. Mestre em Educacão pela Universidade Federal do Río Grande do Sul (Bolsa Capes). Especialista em Teoria Psicanalítica pela UNISINOS. Graduado em Psicologia pela UNISINOS. E-mail: leonidas.taschetto@unilasalle.edu.br. 
BULLYING NO AMBIENTE ESCOLAR:

O PAPEL DO PROFESSOR E DA ESCOLA COMO PROMOTORES DE RESILIENNCIA

\begin{abstract}
This article aims to provoke reflection about school bullying, defined as intentional violent practice practiced among peers, with unequal power, which undermines human relationships, with consequences and changes in bio-psychological characteristics of those involved. The report presents an activity developed by a teacher in a public school in southern Brazil, which asked her students at the beginning of the school year to produce a text entitled: "Who am I?" The text of one of the students about their suffering to go back to school due to bullying motivated the teachers to develop an intervention project. At the end of the school year, a new essay was requested, through which was found the positive development of that student. The account of this experience presents the two essays of the student and the intervention project developed in the school environment.
\end{abstract}

Keywords: Bullying; intervention; risk and protection; resilience.

\title{
1 Introdução
}

O bullying é uma prática violenta e intencional praticada entre pares, com desigualdade de poder, que gera dor e sofrimento para todos os envolvidos. Essa forma de violência constitui ou alimenta uma condição de risco, que pode levar o indivíduo a apresentar desordens de diversos níveis (YUNES; SZYMANSKI, 2001; FANTE, 2012, SCHULTZ et al., 2012).Por provocar tantos males, é importante que a escola não minimize as ocorrências de bullying, devendo potencializar, por meio dos educadores, interações significativas que contribuam para processos de resiliência diante das adversidades encontradas no ambiente escolar (YUNES, 2003; YUNES et al., 2015).

Partindo desse pressuposto, uma professora do Ensino Fundamental de uma escola pública do sul do Brasil, após conhecer a história de um aluno, que relatou, em uma produção textual, seu sofrimento em decorrência de bullying, criou um projeto de intervenção que possibilitasse o desenvolvimento saudável do educando e de outros adolescentes envolvidos com a violência. Ao final do projeto, foi possível constatar que o estudante manifestou expressões de resiliência, e a professora atuou como agente de proteção e tutora de desenvolvimento (CYRULNIK, 2009).

Este artigo propõe-se a relatar uma experiência de intervenção que envolve situações de bullying e visou à promoção de expressões de desenvolvimento positivo e de resiliência. As metodologias e estratégias utilizadas foram de base qualitativa. As duas produções de texto de um mesmo aluno, antes e após o desenvolvimento do projeto de intervenção realizado pela professora responsável pela classe, foram analisadas, e a base das reflexões foi pautada por conceitos da perspectiva bioecológica do desenvolvimento humano $(1979 / 1996 ; 2011)$ apresentada a seguir. 


\section{A teoria bioecológica do desenvolvimento humano}

A teoria bioecológica define o desenvolvimento humano como a interação de uma pessoa em atividade com outras pessoas, objetos e símbolos, em diferentes ambientes, por longos períodos de tempo. Esses ambientes são: a) microssistema, definido como sistemas próximos, de papéis, atividades e relações face a face (família e escola da criança, por exemplo); b) mesossistema, que são as interrelações entre os microssistemas; c) exossistema, os sistemas distais com influência indireta sobre a pessoa (o trabalho dos pais); d) macrossistema, sistema mais distante e que engloba todos os outros (culturas, leis, concepções ideológicas) (BRONFENBRENNER, 1979/1996; SENNA, 2011; PIETRO; YUNES; LIMA, 2014).

A partir disso, é proposto um modelo composto por quatro núcleos: Processo, Pessoa, Contexto e Tempo (PPCT), em que Processo é a fusão e a dinâmica entre o indivíduo e o contexto; Pessoa é a pessoa em desenvolvimento, envolvendo características biológicas, cognitivas, emocionais, comportamentais e aquelas construídas na interação com o ambiente; Contexto são os níveis ou sistemas entrelaçados da ecologia do desenvolvimento humano que influenciam a pessoa em desenvolvimento; Tempo são as mudanças e continuidades da pessoa em desenvolvimento ao longo do tempo (BRONFENBRENNER, 2011; CECCONELLO; KOLLER, 2003; YUNES; JULIANO, 2010; SENNA, 2011).

Sob essa perspectiva, privilegiam-se as análises dos processos proximais, que são formas de interação entre a pessoa em desenvolvimento e o ambiente imediato ao longo do tempo. Tais processos envolvem interações cada vez mais complexas e podem produzir efeitos de competência (positivos) ou disfunção (negativos) (BRONFENBRENNER, 1979/1996; SENNA, 2011). A teoria bioecológica permite a compreensão das díades, definidas como a relação entre duas ou mais pessoas que prestam atenção nas atividades uma da outra ou delas participam, possibilitando o desenvolvimento (saudável ou não). Nessa relação, consideram-se três propriedades fundamentais: Reciprocidade, que trata da influência mútua, com retroalimentação motivacional e coordenação entre as atividades; Equilíbrio de poder, que são as influências de um membro sobre o outro; e Relação afetiva, que trata dos sentimentos de um membro em relação ao outro, sendo o resultado das duas propriedades anteriores (BRONFENBRENNER, 2011; SENNA, 2011).

O modelo bioecológico tem sido utilizado por educadores, psicólogos e profissionais da saúde em estudos com famílias e membros da comunidade escolar, a fim de entender fenômenos complexos, como situações de risco, violência e suas diferentes manifestações (YUNES, 2006; PIETRO; YUNES; LIMA, 2014).

Analisando-se as interações a partir do modelo PPCT, entende-se que Processos são os vínculos entre os contextos (escola e família) e as pessoas envolvidas, as interações, as atividades diárias do adolescente e os papéis desempenhados pelos envolvidos. Pessoa refere-se ao adolescente. Consideram-se 
BULLYING NO AMBIENTE ESCOLAR:

ainda como pessoas os agressores do adolescente, os familiares, os professores e membros da equipe diretiva. Contextos são a escola e a família. Tempo refere-se tanto ao cotidiano do adolescente, mas também à sua história de vida, às experiências do passado e expectativas do futuro.

\section{Bullying no ambiente escolar: definições, manifestações e consequências}

O bullying é definido como a prática violenta e intencional que causa dor, angústia e sofrimento às vítimas (FANTE, 2012; SCHULTZ et al., 2012). Apesar de se manifestar em diferentes contextos, pesquisadores de todo mundo vêm estudando o bullying especificamente na escola e na relação entre os alunos (FANTE, 2012).

Essa forma de violência é tão antiga quanto a própria instituição escolar; contudo, os estudos nessa área são recentes e tiveram início com Dan Olweus, pesquisador norueguês que, na década de 1970, passou a investigar o problema dos autores e suas vítimas na escola (ALMEIDA; FERNÁNDEZ, 2014). Mesmo demonstrando essa preocupação, foi somente na década de 1980, após o suicídio de três adolescentes entre 10 e 14 anos, no norte da Noruega, possivelmente provocado por situações graves de bullying, que as instituições passaram a demonstrar interesse pelo tema (FANTE, 2012).

A palavra bullying, derivada do verbo inglês bully, não tem tradução para a Língua Portuguesa, mas é definida por diferentes autores como "valentão", "tirano", "uso da superioridade para intimidar alguém" (FANTE, 2012; SCHULTZ et al., 2012). Segundo Olweus (1993), há a existência do bullying quando um estudante é vitimizado ou agredido, estando exposto repetidamente e ao longo do tempo a ações negativas por parte de um ou mais estudantes (denominados bullies), tendo como consequências dano e sofrimento aos alvos.

No bullying, as agressões podem ser de forma direta, em que a vítima vê e sabe quem é o agressor, ou indireta, em que a vítima é atacada, mas pode não saber quem é o agressor (OLWEUS, 1993). São formas diretas as agressões físicas (chutar, empurrar, bater, dar pontapés, roubar, empurrar, danificar pertences); verbais (xingar, ameaçar, insultar, humilhar, intimidar, discriminar); sexual (insinuar, assediar, abusar, violentar). São formas indiretas o isolamento ou exclusão da vítima, afetando o relacionamento entre pares, e o cyberbullying (OLWEUS, 1993; FANTE; PEDRA, 2008; FRANCISCO; LIBÓRIO, 2009; FANTE, 2012; SCHULTZ et al., 2012; ALMEIDA, 2014).

As pessoas envolvidas com o fenômeno podem exercer papéis distintos: alvo, alvolautor, autor e testemunha. O alvo é definido como um indivíduo que não tem condições de se defender. $\mathrm{O}$ alvolautor é aquele que reproduz os maus-tratos sofridos em alguém mais frágil que ele, o que faz aumentar o número de vítimas. O autor é aquele que vitimiza os mais fracos, estando numa situação de superioridade. A testemunha é aquela que não participa 
diretamente do bullying, mas presencia as agressões e cala-se por medo de ser a próxima vítima (OLWEUS, 1993; LOPES NETO, 2005; FRANCISCO; LIBÓRIO, 2009; PEREIRA; SILVA; NUNES, 2009; FANTE, 2012).

O bullying pode causar problemas sérios para quem sofre, pratica ou testemunha. Francisco e Libório (2009, p. 201) afirmam que, se "[...] por um lado, as vítimas sofrem uma deterioração da sua autoestima, e do conceito que têm de si, por outro, os agressores também precisam de auxílio, visto que sofrem grave deterioração de sua escala de valores [...]".

Mesmo provocando males, a família e a escola não têm valorizado a gravidade do problema, ao entenderem que as agressões são apenas brincadeiras típicas da idade (FANTE, 2012). Por isso, muitos professores não intervêm durante os episódios violentos presenciados no ambiente escolar, conforme estudo realizado no Canadá por Mishna et al. (2005).

A escola é um ambiente que propicia experiências de relações de hierarquia, vivências de igualdade e convívio com as diferenças, que influenciam a formação do indivíduo (CANTINI, 2004). Devido a essas características, Pietro, Yunes e Lima (2014) consideram que a escola deveria oportunizar a transformação das estruturas sociais, e não apenas responsabilizar-se pela difusão de conhecimentos. É de fundamental importância que a escola não minimize as atitudes violentas que ocorrem em seu ambiente; ao contrário, essas devem ser tratadas e receber a devida atenção e enfrentamento em prol do futuro saudável de seus estudantes. Ademais, o bullying é um fenômeno sistêmico que se manifesta em diferentes sistemas de influência e pode, portanto, ser analisado sob a perspectiva bioecológica (BRONFENBRENNER; 1978/1996; 2011).

\section{0 professor e seu papel de proteção no ambiente escolar}

Na escola, cada professor tem seu modo particular de organizar as aulas e de utilizar os meios pedagógicos que acredita serem os mais apropriados (NÓVOA, 1992). No contato cotidiano com os alunos, ter como qualidade a generosidade é fundamental para estabelecer um ambiente de respeito, em que ambos dialogam com liberdade (FREIRE, 1996) e conduzido por bons tratos (BARUDY; DARTAGNAN, 2005). O profissional da educação deve ter em mente que "[...] a educação é uma forma de intervenção no mundo [...]", a qual vai além dos conteúdos, ao respeitar os conhecimentos dos alunos e escutá-los, para que juntos, a partir dessas experiências, contribuam para a transformação da sociedade (FREIRE, 1996, p. 98).

No microssistema escolar, professores deparam-se, cotidianamente, com situações de bullying, o qual geralmente constitui ou alimenta uma condição de risco, que pode levar o indivíduo a apresentar desordens psicológicas, sociais e cognitivas de diversos níveis (YUNES; SZYMANSKI, 2001). Processos de risco são definidos como "[...] toda a sorte de eventos negativos de vida, e que, quando presentes, aumentam a probabilidade de o indivíduo apresentar problemas físicos, sociais ou emocionais" (YUNES; SZYMANSKI, 2001, p. 24). 
BULLYING NO AMBIENTE ESCOLAR:

Ao contrário dos processos de risco, os processos de proteção "[...] correspondem às influências que modificam, melhoram ou alteram respostas individuais a determinados riscos de desadaptação" (POLLETO; KOLLER, 2006, p. 31) e têm o papel de modificar as respostas diante de situações adversas (YUNES; SZYMANSKI, 2001). Para Rutter (1987), há quatro mecanismos que contribuem para a ocorrência dos processos de proteção: redução do impacto dos riscos, que significa alterar a exposição da pessoa à situação estressora (como o bullying); redução das reações negativas em cadeia que seguem a exposição do indivíduo à situação de risco; estabelecimento e manutenção da autoestima e autoeficácia, por meio da presença de relações de apego, que sejam seguras e incondicionais, e o cumprimento de tarefas com sucesso; criação de oportunidades, que possibilitem uma "virada" na vida da pessoa. Esses mecanismos de proteção podem ser pontos-chave necessários, ou "pontos de virada" - processo que pode modificar os rumos de uma trajetória, tornando o indivíduo adaptado ou desadaptado durante seu ciclo de vida (RUTTER, 1987) - para o restabelecimento do equilíbrio perdido e demonstração de competência apesar da adversidade (JULIANO; YUNES, 2014).

Como resultado desses processos de proteção que se sobrepõem aos riscos, o conceito de resiliência refere-se a "[...] processos que explicam a 'superação' de crises e adversidades em indivíduos, grupos e organizações", o que não quer dizer que o indivíduo saia ileso das crises (YUNES, 2006, p. 76). Além de superação e enfrentamento das situações adversas, resiliência implica em transformações positivas, em metamorfoses pessoais ou coletivas, que advém das vivências pós-crises (YUNES, 2015). Por não se tratar de um atributo individual, crianças e adolescentes que sofrem qualquer forma de violência têm maiores chances de superar as dificuldades e empoderar-se se tiverem à sua disposição uma rede de apoio com "[...] o poder de transformação social da cooperação como atitude que enfatiza pontos comuns em um grupo para gerar benefícios mútuos, solidariedade e parceria" (JULIANO, 2014, p. 26).

Sabe-se que o indivíduo exposto à situação de risco necessita de determinadas situações amortecedoras dos eventos "negativos". Assim, é possível buscar e desenvolver programas que reduzam os riscos e promovam a resiliência (BLUM, 1997). Nesse caso, o professor pode tornar-se um importante aliado de seus alunos nos processos de superação das adversidades decorrentes da violência. Portanto, o docente tem o papel de potencializar "[...] interações significativas que podem contribuir para os processos de resiliência diante de adversidades no/do ambiente escolar [...]", atuando como um agente de proteção (YUNES et al., 2015, p. 159).

Para possibilitar o desenvolvimento humano, é preciso que educadores e alunos dialoguem, realizem atividades conjuntas, interativas, que se tornem cada vez mais complexas, conforme preconiza a teoria bioecológica (SENNA, 2011; BRONFENBRENNER, 2011). Com base nessas elaborações teóricas, serão apresentadas, a seguir, a experiência de superação e as formas de enfrentamento de situações de bullying no ambiente escolar, a partir das situações descritas. 


\section{0 relato escrito de um aluno: da tristeza à superação}

A professora de uma escola municipal do sul do Brasil propôs, no primeiro dia de aula, a produção do texto "Quem sou eu?", com o objetivo de conhecer a vida de seus alunos. Ao ler os textos, chamou atenção a história de um adolescente de 14 anos, que descreveu sua tristeza ao ter que voltar para a escola após as férias. O sofrimento tinha um nome: bullying. A partir do relato, a professora sentiu-se motivada a criar um projeto de intervenção para amenizar os sentimentos daquele aluno e de outros que não tiveram a oportunidade de escrever sobre suas vivências. Ao final do ano, a professora solicitou novamente que um texto fosse produzido pelo mesmo aluno para verificar possíveis mudanças no período pós-intervenção.

\subsection{O primeiro relato do adolescente}

Artur é um menino de 14 anos, que cursa o $7^{\circ}$ ano de uma escola pública municipal do sul do Brasil. $O$ estudante escreveu em seu texto os detalhes sobre a sua angústia de ter que voltar à escola após as férias, pois há tempos vinha sofrendo bullying, devido à sua baixa estatura e tipo físico magro e franzino.

Ao solicitar a escrita do texto, a professora esperava encontrar relatos sobre gostos musicais, atividades preferidas, constituição das famílias, atividades realizadas nas férias. Mas Artur não fez apresentações e iniciou seu texto desta forma: "Fora da escola eu sou uma criança divertida que gosta de brinca mais na escola eu não gosto que me coloquem apelidos isso me deixa triste" (sic). Nesse primeiro momento, já é possível perceber a tristeza do aluno em ter que voltar para a escola, deixando claro que vinha sofrendo bullying há algum tempo. Nesse caso, a escola não está cumprindo com seu papel de protegê-lo da violência, conforme preconiza o Estatuto da Criança e do Adolescente (BRASIL, 1990).

Como forma de disfarce, declarou que ri da situação junto aos seus agressores: "eu não gosto de fala [que se sente mal com os apelidos] dai pra desfarça eu do risada" (sic). Essa atitude de demonstrar que não se importa com os apelidos parece ser uma forma de defesa, com o propósito de evitar mais humilhação por parte de seus agressores. O bullying, recorrentemente, é confundido com brincadeiras, por isso, em muitos casos, esse tipo de comportamento acaba se propagando no meio escolar, e não se adotam medidas de prevenção (FANTE, 2012).

O estudante continua seu relato destacando que na família ele é tratado como igual: "dois dias antes de começa as aulas eu fui viajar para um sitio com ele [o primo] la sim eu me senti avontade com os novos amigo que eu fiz la todos eram igua ninguém te colocava apelido" (sic). Nesse caso, a escola é percebida como um local desagradável, injusto e inseguro (ASSIS, 2005). Portanto, é importante uma mudança nesse ambiente para que esse e outros alunos vislumbrem a escola como um lugar seguro e agradável, e não um palco de sofrimentos, 
BULLYING NO AMBIENTE ESCOLAR:

por mais um ano que se arrastaria, com as agressões verbais e outras formas de violência que podem trazer consequências para a sua vida futura (FANTE, 2012).

Estudos revelam que uma pessoa alvo de bullying pode se tornar um autor, pois tem um desejo de reproduzir os maus-tratos sofridos em alguém mais frágil, em virtude de não conseguir se defender (LOPES NETO, 2005; FANTE, 2012; SHULTZ et al., 2012). Esse é o caso de Artur, o qual, no microssistema família, revela que desconta sua raiva na irmã: "so que dai chego em casa as vezes e desconto minha raiva em meus irma" (sic). Em sala de aula, a professora também já presenciou Artur colocando apelidos pejorativos e insultando os colegas de forma irônica, o que transparece uma espécie de "vingança" do seu sofrimento, causando o mesmo nos outros.

Em seu relato escrito, o adolescente solicita que a professora não conte para ninguém toda a sua angústia: "sora não conte a niguem nem mesmo aos meus pais" (sic). Martins (2005) e Francisco e Libório (2009) destacam que a maioria dos estudantes busca o auxílio dos professores ou dos pais para resolver esse problema de maus-tratos. Artur, então, finaliza seu relato dizendo: "é isso que eu sou de verdade" (sic), o que demonstra o peso dos episódios de bullying na construção da identidade deste adolescente.

Se não conseguir superar o trauma, o alvo, que é o caso de Artur na maioria das vezes, pode desenvolver sentimentos negativos e pensamentos de vingança; ter baixa autoestima, dificuldades de concentração e aprendizagem; queda do rendimento escolar e problemas de relacionamento, entre outros problemas sérios (FANTE; PEDRA, 2008; SHULTZ et al., 2012). Cabe salientar que Artur é aluno repetente, fato que pode estar associado às consequências dos episódios vividos de bullying (FANTE, 2012).

Bronfenbrenner (1979/1996; 2011) destaca a importância de se analisar fenômenos, como a violência, de forma sistêmica, em que atitudes da pessoa em desenvolvimento em um determinado ambiente refletem nos demais e podem perdurar por toda a vida. Nesse caso, constata-se que o bullying sofrido por Artur está refletindo diretamente no microssistema familiar e que suas interações têm produzido efeitos negativos (BRONFENBRENNER, 1979/1996; SENNA, 2011).

Para evitar que o fator de risco bullying estivesse presente na vida de Artur por mais um ano, a professora da escola desenvolveu um projeto de intervenção, embasado em três pressupostos: a) a escola é um espaço de proteção de crianças e adolescentes; b) o ECA (BRASIL, 1990) determina, em seu artigo $5^{\circ}$, que nenhuma criança ou adolescente será objeto de violência; $c$ ) a Lei de Diretrizes e Bases da Educação Nacional (BRASIL, 1996) determina que crianças e adolescentes têm o direito à educação, com vistas ao pleno desenvolvimento de sua pessoa e ao preparo para o exercício da cidadania. 


\subsection{Projeto de intervenção: por uma escola sem violência}

A escola é um ambiente de socialização para crianças e adolescentes e deve ser um espaço seguro, amoroso e estável para favorecer o desenvolvimento pleno dos estudantes. Por isso, precisa denunciar e prevenir atitudes de violência de forma protetiva e orientar estudantes sobre o melhor caminho a seguir (ASSIS, 2005; SCHULTZ, et al.; 2012). Caso contrário, se "[...] os comportamentos de bullying são ignorados, não são reprovados e não têm uma resposta consistente por parte dos profissionais que desempenham funções educativas [...]", a tendência é que aumentem com o passar do tempo (ALMEIDA, 2014, p. 84).

A qualidade das relações é prioridade entre todos os que nela atuam e desenvolvem propostas pedagógicas adequadas às necessidades e ao desenvolvimento saudável dos educandos (YUNES et al., 2015). Para combater a violência na escola, é preciso construir um ambiente favorável, humano e cooperativo, com a criação de relações positivas e duradouras entre todos os envolvidos - alunos, professores, funcionários e comunidade (TAVARES-DOS-SANTOS; MACHADO, 2010).

A partir dessas premissas e após a leitura do texto de Artur, a professora da turma, com a anuência da orientadora educacional, elaborou um projeto de prevenção e combate à violência associado ao objetivo de estudar o fenômeno bullying e outras formas de violência. Foram feitas buscas em leituras de artigos, dissertações, teses e livros que abordam o fenômeno. Além disso, foram realizadas pesquisas no canal Youtube, a fim de selecionar vídeos que abordassem a violência de uma forma geral, a violência nas escolas e projetos de combate ao bullying elaborado por estudantes. ${ }^{1}$

O projeto que será relatado nessa experiência foi desenvolvido, num primeiro momento, em sala de aula. A primeira atividade consistiu em assistir aos vídeos do canal Youtube e ao filme "O contador de histórias", que conta a história de Roberto Carlos Ramos, menino que passou por adversidades, mas as superou e hoje é uma pessoa reconhecida por sua arte de contar histórias.

A partir de então, a professora promoveu um importante debate sobre os vídeos e o filme, momento em que os estudantes demonstraram preocupação com os problemas advindos da violência, mas também reconheceram as possibilidades de superação. Alunos e professora, então, nos momentos de diálogo, base de todas as etapas da intervenção, concluíram que as atitudes violentas entre os colegas deveriam ser erradicadas, para que prevalecesse o respeito e a compreensão das diferenças e singularidades entre indivíduos. Após essa fase de compreensão e reconhecimento do fenômeno de bullying, os alunos produziram um texto, comparando suas histórias de vida com as histórias do filme. Certamente, as atitudes não desapareceram imediata e definitivamente, mas, a cada ocorrência, a professora intervinha e relembrava que a escola deve ser um lugar de respeito, de trocas e de muita conversa e esclarecimentos.

\footnotetext{
1 Vídeos apresentados aos alunos: Documentário Violência Brasileira. Disponível em: https://www. youtube.com/watch?v=GZMQdxad 3k. Não ao bullying. Disponível em: https://www.youtube.com/watch? v=IC4JOqf30UU. Violência nas escolas. Disponível em: https://www.youtube.com/watch?v=Z6IS_WQ0nWg
} 
BULLYING NO AMBIENTE ESCOLAR:

Numa etapa posterior, a turma foi dividida em grupos para elaborarem seus próprios projetos de combate ao bullying. Foram propostas a confecção de folderes sobre o tema e a realização de palestras às crianças e adolescentes da escola, ministradas pelos educandos idealizadores das propostas.

Durante o projeto, Artur demonstrou muito interesse em participar: sugeriu que a turma assistisse ao filme "O contador de histórias" e foi ativo ministrante de palestras para outras turmas. No terceiro trimestre letivo, quatro alunos, incluindo Artur, conduziram mais palestras de combate ao bullying para as turmas de sextos anos. Além disso, em novembro de 2014, esse grupo participou de um evento realizado pela prefeitura municipal de Canoas-RS relativo à prevenção da violência escolar.

Na perspectiva de Bronfenbrenner, "[...] o desenvolvimento ocorre por meio de processos de interação recíproca da pessoa com outras pessoas, objetos e símbolos presentes em seu ambiente imediato, denominados de processos proximais" (CECCONELLO; KOLLER, 2015, p. 211). A partir do projeto, que possibilitou essas formas de interação consideradas fortalecedoras das competências individuais e importantes para o desenvolvimento, Artur passou a demonstrar seu potencial de liderança e enorme interesse nas atividades propostas para auxiliar outros estudantes; portanto, aparentou estar superando suas dificuldades por meio de criatividade e pró-atividade, sendo capaz de reconhecer a escola como um ambiente seguro e de aprendizagem.

Durante esse trabalho, foram relevantes as trocas afetivas e de confiança entre professora, alunos e Artur, elementos fundamentais para a construção das expressões de resiliência, as quais, para Candorelli (2005), contribuem para estruturar vínculos significativos, transmitindo um sentido de aceitação, confiança, acolhimento. Poder-se-ia dizer que a professora, como organizadora da proposta, foi a tutora de desenvolvimento do grupo.

\subsection{0 segundo relato do adolescente}

Ao final do ano letivo, a professora solicitou aos alunos da turma de Artur, novamente, a produção do texto "Quem sou eu?", mesmo título do texto já produzido no início do ano, a fim de analisar as possíveis mudanças no desenvolvimento dos estudantes.

Ao ler o texto de Artur, foi notória a mudança da percepção do adolescente em relação ao ambiente escolar. Seu texto iniciou da seguinte forma: "Desde no início do ano minha vida mudou radicalmente em mim começei a gostar de coisas que eu não gostava tipo ler livros, estudar, etc, nunca na minha vida tinha estudado" (sic). Nesse relato, Artur compara sua vida no início e no final do ano: o fato de passar a gostar de estudar e de ler, expresso textualmente, evidencia o envolvimento de Artur com as atividades escolares, ao contrário do primeiro texto.

Seu texto segue: "conheci novos amigos e os que eu já conheci a gente se aproximamos mais" (sic). Percebe-se mais uma mudança na vida de Artur, 
que é o fato de fazer novos amigos e de se aproximar de outros que antes se distanciavam. No início do ano, o aluno tinha dificuldades de se relacionar; após o projeto, constituiu relações proximais e uma rede de amigos mais ampla, especialmente com colegas integrantes do projeto.

Por fim, ao declarar que "este ano está cendo bem legal" (sic), confirma-se que o projeto de intervenção desenvolvido em sala de aula foi importante para que Artur pudesse visualizar a escola como um ambiente seguro e melhor de conviver.

O caso de Artur revela superação das adversidades causadas por bullying, e, com o auxílio da escola, na figura do professor como um agente de proteção, os alunos que sofrem bullying tornaram-se tutores de resiliência, o que foi o caso do estudante Artur (CYRULNIK, 2015). Nesse sentido, acredita-se que a escola, com boas práticas, e o trabalho atento do professor podem ser uma importante rede de apoio e de promoção de resiliência.

Para que a proposta de intervenção alcançasse resultados satisfatórios, a relação de Artur com os colegas e com a professora foi baseada nas três propriedades fundamentais das interações, de acordo com a bioecologia do desenvolvimento humano: a) Reciprocidade, pois colegas e professora influenciaram-se mutuamente durante as atividades do projeto; b) Equilíbrio de poder, que se alternava liderança entre Artur, colegas e professora durante todas as etapas do trabalho; c) Relação afetiva positiva tanto com colegas, que se tornaram seus amigos, tanto quanto a professora. A mudança de papel desempenhado no microssistema escola fica demonstrada como relevante para o crescimento saudável do aluno e de todos os envolvidos. Além disso, os processos proximais possibilitaram efeitos de competência (BRONFENBRENNER, 2011). Senna (2011), ao apresentar o paradigma sistêmico de Bronfenbrenner, destaca que quem participa de ambientes enriquecedores tem maior possibilidade de absorver conhecimentos do mundo e de adquirir habilidades intelectuais, físicas e socioemocionais.

O projeto desenvolvido em sala de aula pode, então, ser considerado um propulsor de mecanismos de proteção que possibilitou um "ponto de virada" na vida de Artur (e possivelmente de outros educandos), e assim, pode ser capaz de mudar sua trajetória de desenvolvimento de risco para resultados de empoderamento e resiliência (RUTTER, 1987; YUNES; SZYMANSKI, 2001).

\section{Considerações finais}

O bullying é um fenômeno complexo que pode gerar consequências capazes de interferir nos microssistemas fundamentais para crianças e jovens, como escola e família, por longo período de tempo (BRONFENBRENNER, 1979/1996; 2011; YUNES et al., 2015).

Há três formas de se tratar a violência, e nela inclui-se o bullying, dentro das escolas: a repressiva, que propõe a busca a instâncias penais, abandonando o processo pedagógico; a patológica, que atua sobre a violência com olhar clínico; 
BULLYING NO AMBIENTE ESCOLAR:

e a do diálogo, que trata a violência como algo a ser combatido com conversas, como um conteúdo pedagógico (TAVARES-DOS-SANTOS; MACHADO, 2010).

Entende-se que a terceira hipótese é, certamente, a maneira mais eficaz. Para isso, escola e professor devem prevenir atitudes violentas, estimular o desenvolvimento de hábitos e habilidades que propiciem saúde física e mental, promovendo expressões de resiliência. Nesse contexto, é preciso formar agentes de proteção, que modificam condições de risco a que estão expostos crianças e adolescentes vitimizados pelo bullying (YUNES; SZYMANSKI, 2001; YUNES et al., 2015).

O conhecimento de que o aluno estava sofrendo bullying motivou a professora a desenvolver um projeto que contribuísse para o desenvolvimento positivo de todos os envolvidos. Tal relato poderia ter sido ignorado e interpretado como uma mera produção textual se a educadora não se sensibilizasse pela tristeza de seu aluno. Esse é o papel do profissional da educação, para além de ministrante de conteúdos e unidades de ensino.

Portanto, ao final do ano letivo, comprovou-se mais do que a eficácia de um projeto. Artur e seus colegas visualizam a escola como um ambiente agradável e de aprendizagens. Assim, a docente, como mediadora, exerceu sua função de "tutora de resiliência" e criou oportunidades e mecanismos de proteção para os alunos enfrentarem suas dificuldades relacionais.

Modificar rumos do desenvolvimento humano, construir novas representações e elaborar novas narrativas (CANDORELLI, 2015) são possíveis em qualquer etapa da vida e, no caso de Artur, foi em tempo de escrever uma nova história durante a adolescência, período sensível e aberto às mudanças identitárias.

No dia 06 de novembro de 2015, foi sancionada a Lei de Combate ao Bullying (Lei 13.185/15), por meio da qual se institui o Programa de Combate à Intimidação Sistemática (Bullying) em todo o território nacional. Portanto, agora é lei e dever de todos os estabelecimentos de ensino criarem medidas de conscientização, prevenção, diagnose e combate à violência e à intimidação sistemática. É importante reiterar que serão necessários mecanismos de fiscalização para que essa determinação seja efetivamente cumprida e não seja apenas mais uma legislação a ser burlada em nosso país.

\section{Referências}

ALMEIDA, A. T. de. Recomendações para a prevenção do cyberbullying em contexto escolar: uma revisão comentada dos dados da investigação. Educação, Ciência e Cultura, Canoas, v. 19, n. 1, p. 77-91, 2014. Disponível em: <http://www.revistas.unilasalle.edu.br/index.php/ Educacao/article/view/1657/1125>. Acesso em: 10 mar. 2015

ASSIS, S. G. et al. Encarando os desafios da vida: uma conversa com adolescentes. Rio de Janeiro: FIOCRUZ, 2005. Disponível em: <http://www.soperj.org.br/download/encarando\% 20os\%20desafios\%20da\%20vida. pdf>. Acesso em: 20 mar. 2015.

BARUDY, J.; DANTAGNAN, M. Los buenos tratos a la infancia: Parentalidad, apego y resiliência. Barcelona: GEDISA, 2005

BLUM, R. W. Risco e resiliência: sumário para desenvolvimento de um programa. Adolescência latinoamericana, v.1, p. 16-19, 1997. 
BRASIL. Estatuto da Criança e do Adolescente. Lei 8069, de 13 de julho de 1990. Brasília, 1990. Disponível em: <http://www.planalto.gov.br/ccivil_03/leis//8069.htm>. Acesso em: 10 abr. 2015.

Lei 13.185, de 06 de novembro de 2015. Disponível em: <http://pesquisa.in.gov.br/imprensa/jsp/visualiza/ index.jsp?data=09/11/2015\&jornal=1\&pagina=1\&totalArquivos=96>. Acesso em: 25 nov. 2015.

Ministério da Educação. Lei de Diretrizes e Bases da Educação Nacional. Lei 9394, de dezembro de 1996. Brasília, 1996. Disponível em: <http://www.planalto.gov.br/ccivil_03/leis//9394.htm>. Acesso em: 10 mar. 2015.

BRONFENBRENNER, U. A ecologia do desenvolvimento humano: experimentos naturais e planejados. Trad. Maria Adriana Veríssimo Veronese. Posto Alegre: Artes Médicas, 1996 (original publicado em 1979).

Bioecologia do desenvolvimento humano: tornando os seres humanos mais humanos. Trad. André de Carvalho Barreto. Rev. Téc. Sílvia H. Koller. Porto Alegre: Artmed, 2011.

CANDORELLI, A. O florescer do lótus na lama: sobre educação e resiliência In: CABRAL, S.; CYRULNIK, B. (Orgs.). Resiliência: como tirar leite de pedra. São Paulo: Casa do Psicólogo, 2015.

CANTINI, N. Problematizando o "Bullying" para a realidade brasileira. 2004. 206p. Tese (Doutorado em Psicologia) - Pontifícia Universidade Católica de Campinas, 2004. Disponível em: <http://www. bibliotecadigital.puc-campinas.edu.br/tde_arquivos/6/TDE-2012-03-15T050938Z-1719/Publico/Nilza\%20 Catini.pdf>. Acesso em: 05 mai. 2015.

CECCONELLO, A.M., KOLLER, S.H. Inserção ecológica na comunidade: Uma proposta metodológica para o estudo de famílias em situação de risco. Psicologia: Reflexão e Crítica, Porto Alegre, v. 16, n. 3, p. 515-524, 2003. Disponível em: <http://www.scielo.br/pdf/prc/v16n3/v16n3a10.pdf>. Acesso em: 10 out. 2014.

Resiliência: perspectivas conceituais da dimensão. In: CABRAL, S.; CYRULNIK, B. (Orgs.). Resiliência: como tirar leite de pedra. São Paulo: Casa do Psicólogo, 2015. cap. 11, p. 209-226.

CYRULNIK, B. Resiliência: continuar a nascer. In: CABRAL, S.; CYRULNIK, B. (Orgs.). Resiliência: como tirar leite de pedra. São Paulo: Casa do Psicólogo, 2015. cap. 2, p. 33-56.

FANTE, C. Fenômeno bullying: como prevenir a violência nas escolas e educar para a paz. 7. ed. Campinas: Verus, 2012.

FANTE, C.; PEDRA, J.A. Bullying escolar: perguntas e respostas. Porto Alegre: Artmed, 2008.

FRANCISCO, M. V.; LIBÓRIO, R. M. C. Um estudo sobre bullying entre escolares do Ensino Fundamental. Psicologia: Reflexão e Crítica, Porto Alegre, v. 22, n. 2, p. 200-207, 2009. Disponível em: <http://www.scielo.br/pdf/ prc/v22n2/a05v22n2.pdf>. Acesso em: 20 out. 2014.

FREIRE, P. Pedagogia da autonomia: saberes necessários à prática educativa. São Paulo: Paz e Terra, 1996.

JULIANO, M. C. C. Rede família: Uma tecnologia social promotora de resiliência familiar e comunitária. Rio Grande: Pluscom, 2014.

JULIANO, M. C. C.; YUNES, M. A. M. Reflexões sobre rede de apoio social como mecanismo de proteção e promoção de resiliência. Ambiente \& Sociedade, São Paulo, v. XVII, n. 3, p. 135-154, jul.-set. 2014. Disponível em: <http://www.scielo.br/pdf/asoc/v17n3/v17n3a09.pdf>. Acesso em: 10 jan. 2015.

LOPES NETO, A. A. Bullying, comportamento agressivo entre estudantes. Jornal de Pediatria, Rio de Janeiro, v. 81, n. 5, p. 164-172, 2005. Disponível em: <http://www.scielo.br/pdf/jped/v81n5s0/v81n5Sa06>. Acesso em: 20 abr. 2014.

MARTINS, M. J. D. Agressão e vitimação entre adolescentes, em contexto escolar: um estudo empírico. Análise Psicológica, Lisboa, v. 4, n. XXIII, p. 401-425, 2005. Disponível em: <http://www.scielo.mec.pt/pdf/aps/ v23n4/v23n4a05.pdf>. Acesso em: 20 out. 2014.

MISHNA, F. et al. Teachers' understanding of bullying. Canadian Journal of Education, Canadá, v. 28, n. 4, p. 718-738, 2005. Disponível em: <http://www.csse.ca/CJE/Articles/FullText/ CJE28-4/CJE28-4-mishnaetal. pdf>. Acesso em: 19 jun. 2014.

NÓVOA, A. Os professores e as histórias da sua vida. In: (Org.). Vidas de professores. Porto: Porto, 1992. p. 9-30.

OLWEUS, D. Bullying at school. Oxford USA: Blackwell Publishing, 1996. 
BULLYING NO AMBIENTE ESCOLAR:

O PAPEL DO PROFESSOR E DA ESCOLA COMO PROMOTORES DE RESILIENNCIA

PIETRO, A. T.; YUNES, M. A. M.; LIMA, E. D. Programa de intervenção psicoeducacional para professores: a escola como espaço de proteção em casos de abuso sexual. Revista Electrónica de Enseñanza de las Ciencias, Ourense, v. 13, n. 1, p. 1-17, 2014. Disponível em: <http://reec.uvigo.es/volumenes/volumen13/ REEC_13_1_1_ex697.pdf>. Acesso em: 12 jan. 2015.

POLLETO, M.; KOLLER, S. H. Resiliência: uma perspectiva conceitual e histórica. In: DELL'AGLIO, D. D.; KOLLER, S. H.; YUNES, M. A. M. Resiliência e Psicologia Positiva: Interfaces do Risco à Proteção. São Paulo: Casa do Psicólogo, 2006. Parte I, p. 19-44.

RUTTER, M. Psychosocial resilience and protective mechanisms. American Journal of Orthopsychiatry, v. 57, n. 3, p. 316-331, 1987.

SCHULTZ, N. C. W. et al. A compreensão sistêmica do bullying. Psicologia em Estudo, Maringá, v. 17, n. 2, p. 247-254, abr./jun. 2012. Disponível em: <http://www.readcube.com/ articles/10.1590\%2FS1413-73722012000200008>. Acesso em: 20 jun. 2014.

SENNA, M. T. T. R. Pesquisa em Educação Infantil: o paradigma sistêmico de Urie Bronfenbrenner. Curitiba: CRV, 2011.

TAVARES-DOS-SANTOS, J. V. T; MACHADO, E. M. Violência, juventude e reconstrução dos laços sociais. Revista Brasileira de Psicoterapia, Porto Alegre, v. 12, n. 2-3, p. 238-251, 2010. Disponível em: <http://rbp.celg. org.br/detalhe_artigo.asp?id=34>. Acesso em: 16 abr. 2015.

YUNES; M. A. M.; JULIANO, M. C. A Bioecologia do Desenvolvimento Humano e suas Interfaces com Educação Ambiental. Cadernos de Educação, Pelotas, n. 37, p. 347-379, set./dez. 2010. Disponível em: <http:// periodicos.ufpel.edu.br/ojs2/index.php/caduc/article/viewFile/1591/1477>. Acesso em: 10 jul. 2014.

YUNES, M. A. M. Psicologia positiva e resiliência: foco no indivíduo e na família. IN: DELL'AGLIO, D. D.; KOLLER, S. H.; YUNES, M. A. M. Resiliência e Psicologia Positiva: Interfaces do Risco à Proteção. São Paulo: Casa do Psicólogo, 2006. Parte I, p. 45-68.

Psicologia positiva e resiliência. Psicologia em Estudo, Maringá, v. 8, núm. esp., p. 75-84, 2003. Disponível em: <http://www.scielo.br/pdf/pe/v8nspe/v8nesa10.pdf>. Acesso em: 15 jun. 2014.

YUNES, M. A. M.; SZYMANSKI, H. Resiliência: noção, conceitos afins e considerações críticas. In: Tavares J, organizador. Resiliência e educação. 2. ed. São Paulo: Cortez, 2001. p. 13-42.

YUNES, M. A. M. Um educador para proteger do risco e tricotar a resiliência: o profissional da educação como agente de proteção e de promoção de resiliência. In: CABRAL, S.; CYRULNIK, B. (Orgs.). Resiliência: como tirar leite de pedra. São Paulo: Casa do Psicólogo, 2015. p. 157-172. 